\title{
Trends and socioeconomic differences in roll-your-own tobacco use: findings from the ITC Europe Surveys
}

\author{
Abraham K Brown, ${ }^{1}$ Gera E Nagelhout, ${ }^{2,3}$ Bas van den Putte, ${ }^{4,5}$ \\ Marc C Willemsen, ${ }^{2,3}$ Ute Mons, ${ }^{6,7}$ Romain Guignard, ${ }^{8}$ Mary E Thompson ${ }^{9}$
}

\begin{abstract}
- Additional material is published online only. To view please visit the journal online (http://dx.doi.org/10.1136/ tobaccocontrol-2014-051986)

For numbered affiliations see end of article.
\end{abstract}

Correspondence to Dr Abraham K Brown, Division of Marketing, Nottingham Business School, Nottingham Trent University, Nottingham, NG1 4BU, UK;

abraham.brown@ntu.ac.uk

Received 20 August 2014 Accepted 8 May 2015

CrossMark

To cite: Brown AK, Nagelhout GE, van den Putte $\mathrm{B}$, et al. Tob Control 2015;24:iii11-iii16.

\section{ABSTRACT}

Objectives To examine if exclusive Roll-Your-Own (RYO) tobacco use relative to factory-made (FM) cigarette use has been rising over time, to determine the extent to which economic motives and perceptions that RYO cigarettes are less harmful act as primary motivations for use, and to examine the association of income and education with the level of RYO tobacco use among smokers in four European countries.

Methods Data were obtained from the International Tobacco Control (ITC) Europe Surveys, and a cohort sample of 7070 smokers from the Netherlands,

Germany, France and UK were interviewed between June 2006 and December 2012. Generalised estimating equations (GEE) were used to assess trends in RYO use, and whether RYO consumption varied by socioeconomic variables.

Results Exclusive RYO use over the study period has increased significantly in the UK from $26.4 \%$ in 2007 to $32.7 \%$ in 2010 ( $p<0.001)$; France from $12.2 \%$ in 2006 to $19.1 \%$ in $2012(p<0.001)$; and Germany from $12.7 \%$ in 2007 to $18.6 \%$ in 2011 ( $p=0.031$ ), with increased borderline significantly in the Netherlands (31.7\% to $34.3 \%, p=0.052$ ), from 2008 to 2010 . Over three-quarters of users in each of the study countries indicated that lower price was a reason why they smoked RYO. Just over a fourth of smokers in the UK, less than a fifth in France, and around a tenth in Germany and the Netherlands believed that RYO is healthier. Compared with exclusive FM users, exclusive RYO users were more likely to have lower incomes and lower education.

Conclusions Effective tobacco tax regulation is needed in the European Union and elsewhere to eliminate or reduce the price advantage of RYO tobacco. Additional health messages are also required to correct the misperception that RYO tobacco is healthier than FM cigarettes.

\section{INTRODUCTION}

It is well established that raising tobacco taxes can reduce consumption, increase quit attempts among smokers and decrease smoking initiation among youth. ${ }^{1-3}$ However, the tax disparities on different types of tobacco products offer an opportunity for smokers to seek lower priced tobacco products such as Roll-Your-Own (RYO) cigarettes. ${ }^{4}{ }^{5}$ At present, all member states of the European Union tax RYO tobacco at a lower rate than factory-made (FM) cigarettes. $^{6} 7$ In some member states, for example the Netherlands and France, regular premium brands such as Marlboro RYO tobacco, can be easily bought at retail outlets. This provides Marlboro consumers a cheaper option, especially as Marlboro FM cigarettes are becoming increasingly expensive. ${ }^{6} 7$ Such lower priced products undermine the public health impact of tax increases by discouraging consumers from quitting and encouraging them to switch to competitive cheaper brands. ${ }^{3}$ So, in the face of price or tax increases, smokers may engage in less desirable behaviours such as finding cheaper sources of tobacco. ${ }^{8}$

Evidence showed that large numbers of smokers in the EU, particularly those in low-income groups, have been switching from FM cigarettes to RYO tobacco. ${ }^{5} 6$ For example, available data revealed that between 2002 and 2010, consumption of RYO tobacco increased in many EU member states. ${ }^{6}$ An exception to this trend were Belgium and the Netherlands, where per capita consumption of hand-rolling tobacco had been consistently higher than in other member states since 2002 but had decreased slightly by 2010 . It is worthy of note that the availability of relatively cheap RYO tobacco may weaken efforts to reduce smoking prevalence through higher taxes, as some smokers rely on RYO tobacco to continue smoking rather than quitting or cutting down gradually. ${ }^{8-10}$

There are substantial differences in the price of cigarettes. For example, a pack of 20 Marlboro FM cigarettes was $€ 4.99$ in France, $€ 4.17$ in Germany, $€ 3.76$ in the Netherlands and $€ 6.49$ in the UK, in 2010 (prices were standardised by gross domestic product based on purchasing power parity). ${ }^{11}$ Additionally, excise duties on RYO cigarettes for $1 \mathrm{~kg}$ of tobacco are lower than duties on FM cigarettes in member countries. ${ }^{12}$ Nonetheless, between 2011 and 2014, the recorded increase in weighted average price of RYO tobacco in the four main tobacco markets was greater than the corresponding increase in weighted average price of FM cigarettes over this period (see table 1). ${ }^{12}$ In Germany, the weighted average price of RYO per kg increased from $€ 101.33$ to 130.18 (ie, $28.5 \%$ increment) whereas average price of FM tobacco (per 1000 cigarettes) increased between 2011 and 2014 from $€ 229.80$ to 254.50 ( $10.7 \%$ increment). Similarly, a greater increase in weighted average price of RYO (per kg) was recorded in France $(€ 170.28$ to $225.00 ; 32.1 \%$ increment) and the Netherlands ( $€ 116.12$ to $145.09 ; 29.0 \%$ increment) compared to average price of FM tobacco (per 1000 cigarettes) in France ( $€ 270.00$ to $325.00 ; 20.3 \%$ increment) and the Netherlands ( $€ 236.72$ to 291.91 ; $23.3 \%$ increment). We note that though a similar 
Table 1 WAP, specific tax and Ad valorem excise for FM cigarettes and RYO tobacco across study countries

\begin{tabular}{|c|c|c|c|c|c|c|c|c|c|c|c|c|}
\hline \multirow[b]{3}{*}{ Country } & \multicolumn{6}{|c|}{ FM cigarettes } & \multicolumn{6}{|c|}{ RYO tobacco } \\
\hline & \multicolumn{3}{|c|}{ WAP, per 1000 cigarettes, in $€$} & \multicolumn{3}{|c|}{$\begin{array}{l}\text { Specific and Ad valorem } \\
\text { excise, (as \% of WAP) }\end{array}$} & \multicolumn{3}{|c|}{ WAP, per 1000 cigarettes, in $€$} & \multicolumn{3}{|c|}{$\begin{array}{l}\text { Specific and Ad } \\
\text { valoremexcise, (as \% of WAP) }\end{array}$} \\
\hline & 2011 & 2013 & 2014 & 2011 & 2013 & 2014 & 2011 & 2013 & 2014 & 2011 & 2013 & 2014 \\
\hline Germany & 229.80 & 246.50 & 254.50 & 60.65 & 60.10 & 59.58 & 101.33 & 127.80 & 130.18 & 52.18 & 49.72 & 50.54 \\
\hline France & 270.00 & 305.00 & 325.00 & 67.25 & 64.70 & 64.70 & 170.28 & 205.00 & 225.00 & $58.57^{*}$ & 62.00 & 62.00 \\
\hline The Netherlands & 236.72 & 264.62 & 291.91 & 62.70 & 66.55 & 60.54 & 116.12 & 126.86 & 145.09 & 54.46 & 64.45 & 57.25 \\
\hline UK & 313.51 & 407.74 & 420.01 & 73.47 & 70.64 & 69.02 & NA & NA & NA & NA & NA & NA \\
\hline
\end{tabular}

increase in average price of FM cigarettes was recorded in the UK (from $€ 313.51$ to 420.01 ), there was no comparable data for RYO during this period. As such, the recorded higher rise in weighted average price of RYO tobacco compared to FM cigarettes can be seen as a positive development, although the price per gram of RYO tobacco is still less than that of FM cigarettes. Such price differences among tobacco products provide an incentive for the tobacco industry to innovate and exploit preferential excise rates. ${ }^{6} 13$

Despite the price disparities in RYO and FM cigarettes, less is known about the extent to which consumption of lower priced RYO tobacco might affect users over time in European countries. An exception is a recent study that examined RYO use among adult smokers in four high-income countries, ${ }^{5}$ although only one European country (ie, UK) was considered in the study. Aside from the price differential between RYO tobacco and FM cigarettes, smokers tend to roll thinner RYO cigarettes. ${ }^{5}{ }^{14}$ As a consequence, they inhale more deeply to get the same quantity of nicotine, ${ }^{5} 1516$ which may put them at greater risk than other smokers. In addition, smokers may be motivated to use RYO tobacco because of the misperception that RYO products are less harmful than FM cigarettes. ${ }^{15} 16$ This is not surprising, as in the UK and across Europe, tobacco companies have promoted RYO brands as acceptable products. ${ }^{15} 17$ However, studies show that RYO cigarettes are not a safer alternative to FM cigarettes. ${ }^{15} 1618$

Past research has also shown that RYO users tend to be more addicted and younger than FM smokers, and are from lowincome groups. ${ }^{15} 16$ To date, however, there is a scarcity of research assessing the extent to which RYO tobacco is consumed relative to FM cigarettes in Europe, especially among those from deprived communities. We extend the results of an earlier study ${ }^{5}$ in the UK and elsewhere to examine the prevalence of and reasons for using RYO tobacco among adult smokers in four western European countries. Specifically, we seek to address three questions: (1) examine if exclusive RYO tobacco use relative to FM cigarette use has been rising over time, (2) determine the extent to which economic motives and perceptions that RYO cigarettes are less harmful act as primary motivations for use and (3) examine the association of income and education with the level of RYO tobacco use.

\section{METHODS}

\section{Sample}

Participants from the Netherlands, France, Germany and the UK were interviewed as part of the International Tobacco Control (ITC) Europe Surveys. Further information on survey period and sample size of study countries is shown in table 2 . Participants from the UK and Germany were recruited by geographically stratified probability sampling while those from France were recruited by simple random sampling. The Netherlands web sample was drawn from a large probabilitybased database with respondents indicating their willingness to participate in research on a regular basis. ${ }^{19}$ The respondents from Germany and France were surveyed via computer-assisted telephone interview (CATI). In the Netherlands and UK, participants were surveyed via computer-assisted web interviewing and CATI. The respondents lost to attrition were replenished by recruiting additional participants at each wave. There was no replenishment sample in the ITC Germany wave 3 and UK wave 8 data. A full description of the ITC project conceptual framework and methods can be found elsewhere. ${ }^{20} 21$ We defined a smoker as a person who has smoked at least $100 \mathrm{FM}$ or hand-rolled cigarettes in his or her lifetime. In this study, we included only current smokers.

To permit comparisons of smokers' reported use of RYO tobacco between countries, we selected waves occurring at approximately similar times. Therefore, data from the four countries collected between December 2006 and December 2012 were utilised in the analyses. Specifically, survey periods for the data used in the respective countries were: UK (waves 6 -September 2007 to February 2008, 7-October 2008 to July 2009 and 8-July to December 2010), the Netherlands (waves 1-March to April 2008, 3-March to May 2009 and 4-May to June 2010), France (waves 1-December 2006 to February 2007, 2-September to December 2008 and 3-September to December 2012) and Germany (waves 1-July to November 2007, 2-July to October 2009 and 3-September to October 2011). All surveys were approved by the Research Ethics Board

Table 2 Survey period and sample size of current smokers for each International Tobacco Control (ITC) Europe Survey

\begin{tabular}{lllll}
\hline & & \multicolumn{3}{l}{ Sample size } \\
\cline { 3 - 5 } Country & Survey Date & $\begin{array}{l}\text { Period 1 } \\
\text { N (wave) }\end{array}$ & $\begin{array}{l}\text { Period 2 } \\
\text { N (wave) }\end{array}$ & $\begin{array}{l}\text { Period 3 } \\
\text { N (wave) }\end{array}$ \\
\hline UK & $\begin{array}{l}\text { September 2007- } \\
\text { December 2010 }\end{array}$ & $1643(6)$ & $1487(7)$ & $977(8)$ \\
France & $\begin{array}{l}\text { December 2006- } \\
\text { December 2012 }\end{array}$ & $1735(1)$ & $1540(2)$ & $1420(3)$ \\
The Netherlands & March 2008-June 2010 & $2177(1)$ & $1747(3)$ & $1800(4)$ \\
Germany & July 2007-October 2011 & $1515(1)$ & $877(2)$ & $496(3)$ \\
\hline
\end{tabular}


at the University of Waterloo and cleared for ethics at the appropriate Ethics Boards within each country.

\section{MEASURES}

RYO use: All respondents in the UK were asked if they smoked 'FM cigarettes only', 'mainly FM', 'FM and RYO about the same', 'mainly RYO', or 'only RYO'. In France, Germany and the Netherlands, smokers were asked whether they smoked 'FM only', 'RYO only', or 'both RYO and FM'. For the present analysis, smokers were categorised as FM only, RYO only and both RYO and FM.

Reasons for smoking RYO: This was a multiple response variable, and asked respondents who smoked RYO cigarettes to identify up to four reasons from a list: they are cheaper; the taste; they help you reduce the amount smoked; and they are not as bad for your health. We did not use the item 'because they help you reduce the amount smoked' in all countries as this was not asked repeatedly. Moreover, it is worthy of note that in the Netherlands, we could not assess all reasons for use of RYO tobacco: the item 'because they are not as bad for your health' was asked only at the first wave.

\section{Income and education}

Respondents from the Netherlands and the UK were asked about their gross household income per month. However, respondents from Germany and France were asked about their net household income. To permit comparison across countries, income was transformed into a four-point scale (ie, low, medium, high and no answer). To accomplish this, income was first categorised into three levels to determine tertiles for each country (ie, low, medium and high), and participants who did not answer were recorded in a separate category (ie, no answer). Similarly, education was categorised into three levels (low, medium and high) based on the distribution of the data to approximate tertiles. The educational levels did not have a 'no answer' category and were only partly comparable across countries because of differences in educational systems.

\section{Covariates}

Control variables were gender, age and heaviness of smoking index (HSI) ranging from 0 to 6. A four-point scale (ie, within the next month, within the next 6 months, sometime in the future/beyond 6 months and not planning to quit), based on the stages of change, ${ }^{22}$ was used to capture quit intentions, and for analyses was dichotomised to express whether or not smokers had any intention to quit in the next 6 months.

\section{ANALYSES}

An initial cohort of 7070 adult smokers (aged 18 years and older), followed over three time periods in each country, that is, the Netherlands $(n=2177)$, France $(n=1735)$, Germany $(n=1515)$ and the UK $(n=1643)$, was employed in the analyses. Replenishment samples were used between waves to compensate for attrition. All analyses were based on weighted data to ensure that the sample is represented in proportion to the target population with respect to key variables in all countries. Univariate analyses were carried out to explore self-reported prevalence of RYO consumption for each country. To assess the relationship between the outcome variable and each covariate, bivariate analyses were performed. Multivariate analyses were also performed via generalised estimating equations (GEEs) to estimate parameters for the correlated data using binary logistic models. GEE analyses were also performed by country (and between countries), with exclusive use of RYO or FM cigarettes (outcome variable) modelled as a function of key covariates. For all GEE analyses, the working correlation with $\log$ quasilikelihood function under the unstructured model was used because this is assumed to approximate the true correlation structure. ${ }^{23-25}$ The statistical package SPSS V.21 was used for all analyses.

\section{RESULTS}

\section{Trends in the prevalence of RYO use}

The prevalence of RYO and FM use by country across waves is presented in table 3 . Results showed that the proportion of smokers in the UK exclusively using RYO tobacco had increased significantly from $26.4 \%$ in 2007 to $32.7 \%$ in 2010 ( $p<0.001$ ). Exclusive use of RYO increased in France from $12.2 \%$ in 2006 to $19.1 \%$ in $2012(\mathrm{p}<0.001)$ and in Germany from $12.7 \%$ in 2007 to $18.6 \%$ in 2011 ( $p=0.031)$. However, although the proportion of exclusive RYO use was highest across waves in the Netherlands, borderline significance was observed over time (ie, from 2008 to 2010) in this country.

\section{Reported reasons for using RYO cigarettes}

Figure 1 revealed that at period 1, more than $90 \%$ of smokers in the UK and France, respectively, as well as just over $85 \%$ in Germany and approximately $80 \%$ in the Netherlands, indicated that price consideration was a reason why they smoked RYO. In terms of health reasons for using RYO tobacco, just over a fourth of smokers in the UK indicated that they consumed RYO because they think it is healthier than FM cigarettes. In France, about a fifth reported perceived health reasons for using RYO. In Germany, just over a tenth of smokers think that it is healthier. In the Netherlands, $8.6 \%$ of smokers believed that RYO is healthier. In regard to taste reasons, just under two-thirds of smokers in the UK, over three-quarters in the Netherlands, above two-fifths in Germany and a third in France indicated that they consumed RYO because of taste.

\section{Socioeconomic differences in exclusive RYO use}

On account that we found strong significant country $\times$ wave interaction in an omnibus analysis (data not shown), we also performed separate GEE analyses for each country (see online supplementary table $\mathrm{S} 4$ below).

Overall comparisons by income levels between exclusive RYO users and exclusive FM users revealed that smokers with high income were less likely to consume only RYO tobacco than those with low income (OR=0.77, CI 0.69 to 0.86). Within-country comparisons also revealed similar findings, as across all countries, high-income earners were less likely to consume RYO tobacco compared to their low income counterparts (UK: $\mathrm{OR}=0.73$, CI 0.64 to 0.86 ; FR: $\mathrm{OR}=0.62$, CI 0.48 to 0.81 ; NL: $\mathrm{OR}=0.83$; CI 0.70 to $0.97 ; \mathrm{DE}: \mathrm{OR}=0.73, \mathrm{CI}$ 0.56 to 0.96 ).

In terms of education, overall comparisons of exclusive RYO users with FM only users revealed that exclusive RYO users with medium and high education were less likely to consume RYO tobacco than those with low education (high education: $\mathrm{OR}=0.68$, CI 0.60 to 0.77 ; medium education: $\mathrm{OR}=0.79$, CI 0.72 to 0.88 ). Similar findings were reported in France and the Netherlands, respectively, as smokers with medium and high education were less likely to smoke RYO tobacco than those with low education, in both countries (France (high education): $\mathrm{OR}=0.67$, CI 0.50 to 0.87 , medium education: $\mathrm{OR}=0.73$, CI 0.58 to 0.90 ; and the Netherlands (high education): $\mathrm{OR}=0.68$, CI 0.58 to 0.82 , medium education: $\mathrm{OR}=0.43$, CI 0.34 to $0.53)$. We also found that smokers in the UK with medium 
Table 3 Prevalence (\%) of exclusive factory made (FM) use, both Roll-Your-Own (RYO) and FM use, and exclusive RYO use by country and across waves (weighted data)

\begin{tabular}{|c|c|c|c|c|c|c|c|c|c|c|c|c|}
\hline \multirow[b]{2}{*}{ Period } & \multicolumn{3}{|l|}{ UK } & \multicolumn{3}{|l|}{ France } & \multicolumn{3}{|c|}{ Netherlands } & \multicolumn{3}{|l|}{ Germany } \\
\hline & FM only & RYO only & $\begin{array}{l}\text { Both } \\
\text { RYO+FM }\end{array}$ & FM only & RYO only & $\begin{array}{l}\text { Both } \\
\text { RYO+FM }\end{array}$ & FM only & RYO only & $\begin{array}{l}\text { Both } \\
\text { RYO+FM }\end{array}$ & FM only & RYO only & $\begin{array}{l}\text { Both } \\
\text { RYO+FM }\end{array}$ \\
\hline 1 & 62.3 & 26.4 & 11.2 & 72.8 & 12.2 & 15.0 & 45.2 & 31.7 & 23.1 & 72.7 & 12.7 & 14.6 \\
\hline 2 & 62.1 & 25.0 & 12.7 & 72.2 & 13.1 & 14.8 & 44.9 & 33.0 & 22.1 & 72.0 & 14.3 & 13.7 \\
\hline 3 & 60.0 & 32.7 & 7.3 & 65.8 & 19.1 & 15.1 & 44.0 & 34.3 & 21.7 & 70.7 & 18.6 & 10.7 \\
\hline$p$ Value for trend & 0.057 & $<0.001$ & 0.040 & $<0.001$ & $<0.001$ & 0.932 & 0.842 & 0.052 & 0.278 & 0.068 & 0.031 & 0.002 \\
\hline
\end{tabular}

education were less likely to smoke RYO only, compared to smokers with low education ( $\mathrm{OR}=0.80$, CI 0.68 to 0.95$)$, while use by education level was not statistically different in Germany.

Overall comparisons of exclusive RYO use with FM-only use by gender indicated that exclusive RYO users were less likely to be females $(\mathrm{OR}=0.38$, CI 0.34 to 0.42$)$. Within-country comparisons showed similar findings in all countries.

Comparisons by age showed that, overall, smokers aged 25$39,40-54$ and $55+$ were more likely to smoke RYO tobacco exclusively than those aged $18-24(\mathrm{OR}=1.60$, CI 1.31 to 1.96 ; $\mathrm{OR}=2.41$, CI 1.98 to 2.92 ; $\mathrm{OR}=1.73$, CI 1.41 to 2.12 , respectively). Within-country analyses as well revealed that in the Netherlands, those aged 25-39, 40-54 and 55+ years were more likely to smoke RYO exclusively $(\mathrm{OR}=4.50$, CI 2.92 to 7.25; $\mathrm{OR}=10.92$, $\mathrm{CI} 8.92$ to $12.22 ; \mathrm{OR}=14.44$, CI 11.25 to 16.56, respectively), compared to smokers aged 18-24. Similarly, in France and Germany, exclusive RYO users tended to be older smokers aged 25-39 and 40-54 (FR: OR=1.83, CI 1.29 to 2.61 ; $\mathrm{OR}=2.10$, CI 1.47 to 3.01 ; and $\mathrm{DE}: \mathrm{OR}=1.94$, CI 1.12 to $3.36 ; \mathrm{OR}=3.09$, CI 1.82 to 5.25 ), respectively. However, in the UK, users aged 40-54 and 55+ respectively, were less likely to smoke RYO tobacco exclusively than those aged $18-24(\mathrm{OR}=0.66$, CI 0.48 to $0.91 ; \mathrm{OR}=0.49$, CI 0.35 to $0.70)$.

Use of exclusive RYO compared to FM-only use overall showed that consumers with HSI score of 2-4 and 5-6 were more likely to use only RYO cigarettes (HSI 2-4: OR $=1.32$, CI 1.22 to 1.44 ; and HSI $5-6$ : OR=1.37, CI 1.21 to 1.55 , respectively), than those with a HSI score of $0-1$. This result was similar in the Netherlands and Germany, that is, those who had a HSI score of $2-4$ and 5-6, had a greater probability of being exclusive RYO smokers (NL: $\mathrm{OR}=1.81$, CI 1.47 to 2.22; $\mathrm{OR}=1.52$, CI 1.33 to 1.74 ; and $\mathrm{DE}: \mathrm{OR}=1.30$, CI 1.08 to $1.57 ; \mathrm{OR}=1.40$, CI 1.01 to 1.94 , respectively), though in the

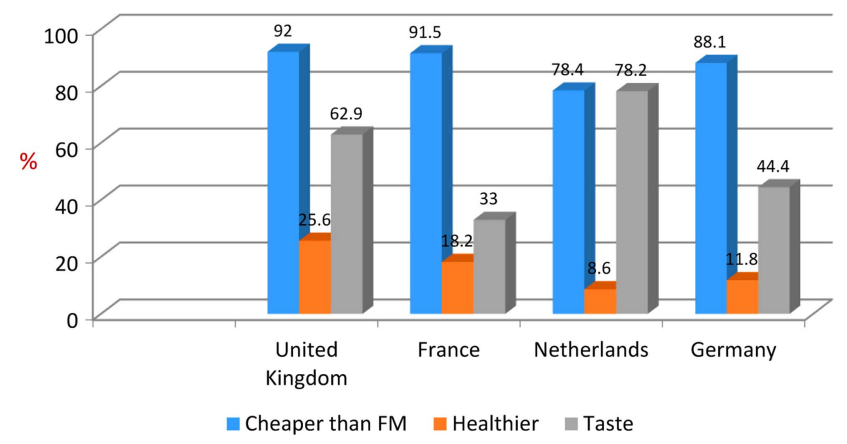

Figure 1 Self-reported (\%) reasons for smoking Roll-Your-Own (RYO) (all RYO users, period 1, weighted data, dichotomous responses).
UK and France only those with a HSI score of 2-4 were significantly more likely to smoke RYO tobacco exclusively (UK: $\mathrm{OR}=1.27$, CI 1.10 to 1.46 ; and FR: $\mathrm{OR}=1.24$, CI 1.03 to 1.51). Overall, smokers who reported an intention to quit in the next 6 months were less likely to smoke RYO tobacco only $(\mathrm{OR}=0.88$, CI 0.84 to 0.93$)$. Significant within-country variations in exclusive RYO use were reported in France and the Netherlands as smokers who had quit intentions were less likely to smoke RYO tobacco only (FR: $\mathrm{OR}=0.82$, CI 0.72 to 0.94 , and NL: $\mathrm{OR}=0.87$, CI 0.80 to 0.95 ). No significant withincountry relationships were found in the remaining countries by quit intentions.

\section{DISCUSSION}

This study depicted that the trend in exclusive RYO use was increasing in the UK, France and Germany, consistent with a previous study. ${ }^{5}$ However, although exclusive RYO use was highest over the study period in the Netherlands, borderline significance with respect to an increase in RYO use was observed in this country. Our results are consistent with demonstrable evidence that the share of fine-cut tobacco (ie, RYO and make-your-own) as a proportion of total tobacco consumption has risen in the European Union, with a corresponding reduction in the share of FM cigarettes. ${ }^{6}{ }^{7}$ Indeed, available data on alternative cigarettes ${ }^{26}$ showed that the countries studied are among the six main RYO tobacco markets in the EU, with $80 \%$ in volume of the EU fine-cut RYO tobacco market. Our findings are also consistent with EU tobacco market data, which depicted that the volume of EU FM cigarettes market in $2010(608.8$ billion sticks) declined by $23.3 \%$ in comparison to $2000 .^{27}$ However, the market size of RYO tobacco in 2010 (75.500 tonnes) increased in comparison to 2000 by $42.2 \%$. In this respect, the EU market for RYO tobacco seems to grow while the market for FM cigarettes seems to decrease.

The relatively lower price of RYO tobacco was significantly the most commonly cited reason for using RYO tobacco, with over three quarters of users in the UK, France, Germany and the Netherlands, indicating that cheaper price was a reason why RYO tobacco was smoked. ${ }^{5}$ The findings reflect the tax differential in the $\mathrm{EU},{ }^{28}$ which allows member states to tax manufactured cigarettes significantly more highly than RYO tobacco. Thus, there is a tendency for consumers to avoid higher priced tobacco products by switching to low-cost alternatives.

In regard to health considerations, around a fourth of smokers in the UK, under a fifth in France and around a tenth in Germany and the Netherlands, reported that they used RYO because it is healthier. Although the proportions of respondents who think that RYO 'is healthier' than FM cigarettes are relatively small, even the smallest proportion reported (ie, 8.6\%) 
translates into many thousands of smokers who hold such misperceptions. Moreover, even though both RYO and FM cigarettes are equally deadly, smokers who hold such misperceptions are likely to consider RYO tobacco as a safer alternative to smoking cigarettes instead of quitting. As such, changing misperceptions surrounding RYO tobacco will not only discourage smokers who are worried about the health consequences of smoking from switching to alternative cigarettes, but may also help RYO smokers to desist from using such forms of tobacco altogether. ${ }^{35}$ Additional health messages are therefore needed to correct the misperception of health benefits of RYO tobacco. Consistent with past study, ${ }^{5}$ we found that approximately two-thirds of smokers in the UK, around three-quarters in the Netherlands, just over two-fifth in Germany and a third in France, indicated that they consumed RYO because of taste.

The pattern of exclusive RYO use compared to exclusive FM use by income and education profile (both within and between the study countries) revealed that exclusive RYO users were more likely to be low-income earners and to have low levels of education. These findings suggest that the availability of lower priced tobacco products such as RYO cigarettes makes smoking more affordable for them and therefore they may experience less economic pressure to quit smoking. Our findings also imply that if cigarettes become more expensive, the availability of lower priced alternative cigarettes may encourage FM smokers to switch to RYO tobacco, instead of choosing the more healthy option to quit. ${ }^{5}{ }^{26}{ }^{28}$ In consequence, efforts aimed at eliminating or reducing the price disparities and availability of these cheaper alternatives are required to prevent substitution in tobacco use.

We found that, overall, exclusive RYO use was strongest among older smokers compared to their younger counterparts. One possible reason why overall older consumers tended to smoke RYO tobacco only could be that this has become habitual. We also found that, overall, exclusive RYO consumers tended to be males and heavy smokers, which is consistent with past research. ${ }^{5} 15$

This study is not without caveats. First, we had a relatively small number of RYO smokers in any given wave, especially in Germany and the UK. As such, examining changes in smokers' choice of RYO and/or FM tobacco consumption over time is somewhat problematic. To resolve this, we used a GEE technique to assess aggregate changes in tobacco use over the study period. This approach also allowed for interwave correlation. Apart from this, the measures we assessed were obtained via self-report responses of smokers and therefore could not be validated by other means. We also noted that the attrition rates in the UK (at period 3) and Germany (at period 2 and period 3) were large. In fact, attrition occurred in all of the countries, but the samples in France and the Netherlands were replenished at periods 2 and 3, and the UK sample was replenished at period 2. Use of weighted GEE analysis controlling for age, gender, HSI and quit intentions not only enabled longitudinal data to be analysed efficiently, with reliable and robust estimates produced, even with incomplete data, but also adjusted for some of the main variables known to influence attrition.

Despite the above caveats, the current prevalence level $l^{5} 29$ and our results provide further support for the fact that EU Member States should not be allowed to price and tax manufactured and alternative tobacco products differently. In this regard, strong tobacco tax regulation is needed in the EU and elsewhere to eliminate or reduce the price advantage of RYO tobacco over FM cigarettes. Importantly, such a strategy should ensure that illicit alternative tobacco does not proliferate. More so, appropriate strategies should be put in place to reduce the adverse economic consequences on low-income smokers who may not be able to quit smoking. To the extent that changing misperceptions surrounding RYO tobacco may encourage smokers who want to stop smoking to quit or reduce consumption, effective tobacco policies that target smokers with additional health messages are required to correct misperceptions of RYO tobacco.

\section{What this paper adds}

- Trends in exclusive Roll-Your-Own (RYO) tobacco use have been increasing significantly in the UK, France and Germany, and borderline significantly in the Netherlands. Use in the Netherlands was highest across waves.

- The relatively lower price of RYO tobacco was the most commonly cited reason for using RYO tobacco, with over three quarters of users in the UK, France, Germany and the Netherlands indicating that they consumed RYO because it was cheaper than factory-made (FM) cigarettes. The misperception that RYO products are less harmful than FM cigarettes still exists among a large number of smokers (especially in the UK). In each of the study countries, low-income earners were more likely to consume exclusive RYO tobacco than high-income earners.

- Tobacco control advocates should aim at establishing effective tobacco tax policy in the European Union and elsewhere to eliminate or reduce the price advantage of RYO tobacco over FM cigarettes.

\section{Author affiliations}

${ }^{1}$ Division of Marketing, Nottingham Business School, Nottingham Trent University, Nottingham, UK

${ }^{2}$ Department of Health Promotion, Maastricht University (CAPHRI), Maastricht, The Netherlands

${ }^{3}$ Dutch Alliance for a Smokefree Society, The Hague, The Netherlands

${ }^{4}$ Department of Communication, University of Amsterdam (ASCoR), Amsterdam, The Netherlands

${ }^{5}$ Trimbos Institute, Netherlands Institute for Mental Health and Addiction, Utrecht, The Netherlands

${ }^{6}$ Division of Clinical Epidemiology and Aging Research, German Cancer Research Center (DKFZ), Heidelberg, Germany

${ }^{7}$ Unit Cancer Prevention, German Cancer Research Center (DKFZ), Heidelberg, Germany

${ }^{8}$ French Institute for Health Promotion and Health Education (INPES), Saint-Denis, France

${ }^{9}$ Department of Statistics and Actuarial Science, University of Waterloo, Waterloo, Canada

Twitter follow Gera E Nagelhout at @geranagelhout

Acknowledgements The authors would like to thank Pete R Driezen for preparing the data in a long format for analyses. The authors also thank Frank J Chaloupka for providing some useful advice on the design of the study.

Contributors The lead author performed the statistical analyses and wrote the manuscript. All authors contributed to successive drafts. The final manuscript was approved by all authors.

Funding The data collection for the ITC Europe Surveys is supported by grants R01 CA 100362 and P50 CA111236 (Roswell Park Transdisciplinary Tobacco Use Research (enter), and P01 CA138389, R01 (A090955) from the National Cancer Institute of the USA, Robert Wood Johnson Foundation (045734), Canadian Institutes of Health Research (57897, 79551 and 115016), the French Institute for Health Promotion and Health Education (INPES), the French National Cancer Institute (INCa), the Netherlands Organisation for Health Research and Development (ZonMw) (the Netherlands), German Federal Ministry of Health, Dieter 
Mennekes-Umweltstiftung and Germany Cancer Research Center (DKFZ); Cancer Research UK (C312/A3726, C312/A6465, C321/A11039, C312/A11943) and the SILNE Project is funded by the European Commission through FP7

HEALTH-F3-2011-278273.

Competing interests None declared.

Patient consent Obtained.

Ethics approval The ITC Europe Surveys were cleared for ethics by Research Ethics Boards or International Review Boards at the University of Waterloo, Canada; University of Stirling and The University of Nottingham, UK; and the appropriate Ethics Boards in the remaining countries.

Provenance and peer review Not commissioned; externally peer reviewed.

Data sharing statement The data used for this study are available on request from the ITC Project at the University of Waterloo, Ontario, Canada.

\section{REFERENCES}

1 Siahpush M, Wakefield MA, Spittal MJ, et al. Taxation reduces social disparities in adult smoking prevalence. Am J Prev Med 2009;36:285-91.

2 Dunlop SM, Cotter T, Perez D. Impact of the 2010 tobacco tax increase in Australia on shortterm smoking cessation: a continuous tracking survey. Med J Aust 2011b;195:469-72.

3 Chaloupka FJ, Straif K, Leon ME. Effectiveness of tax and price policies in tobacco control. Tob Control 2011;20:235-8.

4 Morris S, Tynan MA. Fiscal and policy implications of Selling pipe tobacco for roll-your- own cigarettes in the United States. PLOS ONE 2012;7:e36487.

5 Young $\mathrm{D}$, Yong HH, Borland $\mathrm{R}$, et al. Trends in roll-your-own smoking: findings from the ITC four-country survey (2002-2008). J Environ Public Health 2012;2012:406283.

6 International Agency for Cancer Research. Pricing policy and control of tobacco in Europe. Policy recommendations for tobacco taxation in the European Union. Integrated Research Findings from the PPACTE project, 2014.

7 Gallus S, Lugo A, Ghislandi S, et al. Roll-your-own cigarettes in Europe: use, weight and implications for fiscal policies. Eur I Cancer Prev 2014;23:186-92.

8 Licht AS, Hyland AJ, O'Connor RJ, et al. Socio-economic variation in price minimizing behaviors: findings from the International Tobacco Control (ITC) Four Country Survey. Int. J Environ Res Public Health 2011;8:234-52.

9 Engeland A, Haldorsen T, Andersen A, et al. The impact of smoking habits on lung cancer risk: 28 years' observation of 26,000 Norwegian men and women. Cancer Causes Control 1996;7:366-76.

10 De Stefani E, Oreggia F, Rivero $S$, et al. Hand-rolled cigarette smoking and risk of cancer of the mouth, pharynx, and larynx. Cancer 1992;70:679-82.

11 Currie L, Townsend J, Leon Roux M, et al. Policy recommendations for tobacco taxation in the European Union integrated research findings from the PPACTE project. February 2009 to March 2012. International Agency for Cancer Research. World Health Organisation, 2012. https://www.academia.edu/1257661/Policy_ Recommendations_for_Tobacco_Taxation_in_the_European_Union_Integrated research_findings_from_the_PPACTE_project
12 European Commission. Excise duties on alcohol, tobacco and energy. Manufactured tobacco: Excise duty rates. Excise duties tables. From 2006 to 2015. http://ec. europa.eu/taxation_customs/taxation/excise_duties/index_en.htm

13 Connolly GN, Alpert HR. Trends in the use of cigarettes and other tobacco products, 2000-2007. JAMA 2008;99:2629-30.

14 Laugesen M, Epton M, Frampton CM, et al. Hand-rolled cigarette smoking patterns compared with factory-made cigarette smoking in New Zealand men. BMC Public Health 2009:9:194.

15 Young D, Borland R, Hammond D, et al. Prevalence attributes of roll-your-own smokers in the International Tobacco Control (ITC) Four Country Survey. Tob Control 2006;15(Suppl. III):iii76-82.

16 O'Connor RJ, Mc Neill A, Borland R, et al. Smoker's beliefs about the relative safety of other tobacco products: findings from the ITC collaboration. Nic Tob Res 2007:9:1033-42.

17 Robinson S, Bugler C. General Lifestyle Survey: Smoking and Drinking Among Adults. Newport, UK: Office for National Statistics, 2010.

18 Shahab L, West R, McNeill A. A comparison of exposure to carcinogens among roll-your-own and factory-made cigarette smokers. Addict Biol 2009;14:315-20.

19 Nagelhout GE, Willemsen MC, Thompson ME, et al. Is web interviewing a good alternative to telephone interviewing? Findings from the International Tobacco Control (ITC) Netherlands Survey. BMC Public Health 2010;10:351.

20 Thompson ME, Fong GT, Hammond D, et al. Methods of the International Tobacco Control (ITC) Four Country Survey. Tob Control 2006;15(suppl III):iii12-18.

21 Fong GT, Cummings M, Borland R, et al. The conceptual framework of the International Tobacco Control (ITC) Policy Evaluation Project. Tob Control 2006;15 (Suppl 3):3-11.

22 de Vries H, Mudde AN. Predicting stage transitions for smoking cessation applying the attitude social influence efficacy model. Psychol Health 1998;13:369-85.

23 Hin L-Y, Carey VJ, Wang YG. Criteria for working-correlation-structure selection in GEE: Assessment via simulation. The American Statistician 2007;61:4.

24 Diggle $\mathrm{P}$, Heagerty $\mathrm{P}$, Liang K-Y, et al. Analysis of longitudinal data. 2nd edn. Oxford: Oxford University Press, 2002.

25 Ballinger GA. Using generalized estimating equations for longitudinal data analysis. Organisational Res Meth 2004;7:127-50.

26 Chaloupka FJ, Straif K, Leon ME, Working Group, International Agency for Research on Cancer (IARC). Effectiveness of tax and price policies for tobacco control. IARC Handbook of Cancer Prevention. Tob Control 2011;20:235-8.

27 European Commission. Impact assessment. Commission staff working document. Proposal for a Directive of the European parliament and of the council on the approximation of the laws, regulations and administrative provisions of the Member States concerning the manufacture, presentation and sale of tobacco and related products. 2012.

28 European Commission. Proposals to amend EU Directives on the rates and structure of taxes on manufactured tobacco. Amending Directives 92/79/EEC, 92/80/EEC and 95/59/EEC on the structure and rates of excise duty applied on manufactured tobacco. 2009, 4.

29 Rosenberry ZR, Strasser AA, Canlas LL, et al. Make your own cigarettes: Characteristics of the product and the consumer. Nicotine Tob Res 2013;15:1453-7. 